\title{
Dynamic force signal analysis in dry finish turning of Aluminium metal matrix composites
}

\author{
Srinivasa Rohit. $\mathrm{V}^{1, *}$, Venu Gopal Anne ${ }^{1}$, and Ramakrishna $\mathrm{L}^{2}$ \\ ${ }^{1}$ MED, NIT Warangal, Telangana, India \\ ${ }^{2}$ ARCI, Hyderabad, Telanga, India
}

\begin{abstract}
Metal matrix composites (MMC) have found wide applications in the transportation sector. But, the presence of hard particles in the MMCs causes catastrophic tool failures. The current study presents a method to select process parameters to increase the material removal rate in finish turning of Al-MMC (Al $6061,5 \% \mathrm{SiC}, 3 \% \mathrm{C}$ ) using TiN coated carbide inserts. The key aspects of the method are (a) Using the fractional factorial method for performing experiments economically (b) Using radial force instead of cutting force (c) Using frame statistics and linear spectrum of the radial cutting force signal to select process parameters. The experiments were conducted on a precision lathe. A 6-component piezoelectric dynamometer was used to measure the cutting force.
\end{abstract}

\section{Introduction}

The automotive sector uses metal matrix composites (MMCs) to improve fuel economy and performance of the vehicle [1]. In particular, Aluminium-based MMCs are being widely used because of their high strength-toweight ratio, good thermal conductivity and greater resistance to environmental degradation. However, due to the presence of hard and abrasive particles, machining of MMC results in high tool wear and inferior surface finish [2]. For increasing material removal rate in machining $\mathrm{MMC}$, analysis of the process and selection of process parameters is essential.

The process parameters are generally selected using the following process:

1. Conduct experiments efficiently using design of experiments.

2. Measure the process output using average cutting force, surface roughness or tool wear ${ }^{[3,4]}$.

3. Use optimization techniques to select process parameters based on an objective like maximum material removal rate, lowest machining time or maximum tool life. ${ }^{[5-8]}$

Taguchi method [9] is commonly used to design and identify process parameters. However, Box et al [10], mentions the key limitation of Taguchi method as picking an optimum based on one shot experiment. They suggest the use of limited runs and using graphical analysis as a better approach for initial experimentation. Hence, the current study uses the fractional factorial method with 2-levels and a center-point that is repeated twice. In addition, graphical analysis is used instead of optimization methods that require large number of experiments
Machinability and tool wear studies on MMC have highlighted issues of accelerated tool wear $[11,12]$. Ravi and Singh [13] have presented a review of turning metal matrix composites, discussing the issues of tool-particle interactions and wear mechanisms. The effect of the percentage composition of $\mathrm{SiC}$ particles on tool wear has been studied by Tamer et al [14]. Common measures of output like average cutting force do not provide information about the dynamics of the process. Tlusty et al [15], Tonshoff et al [16], Byrne et al [17] and Teti [18] reviewed statistical and frequency analysis methods in sensor signal analysis for tool condition monitoring. The current study uses frame statistics and linear spectrum to measure the dynamic nature of the process.

Cutting force is commonly used to estimate the power consumed during the process. However, in the case of finish turning, as the cutting forces are low, the current study uses radial force, which is more sensitive to vibrations due to the impact of hard particles in MMCs.

\section{Method}

Dry turning of MMC using coated carbide tools was carried out on a lathe based on the fractional factorial design. The data collected from these experiments was divided into small frames and statistical parameters were analysed. The data was summarized into tables and graphs to aid decision-making.

\subsection{Materials and experimental setup}

The experiments were conducted on a precision lathe (Make: Magnum SSM 1430) with a 6-component

\footnotetext{
* Corresponding author: vsrohit@gmail.com
} 
piezoelectric dynamometer as shown in Fig. 1. Al- MMC $(6 \% \mathrm{SiC}$ and $3 \% \mathrm{C})$ of diameter $35 \mathrm{~mm}$ was used as the workpiece. A TiN coated carbide insert (Widia CNMG 120408TN-4000) connected to a tol holder (Taguetec PCBNR 2525M12) was used as a cutting tool.

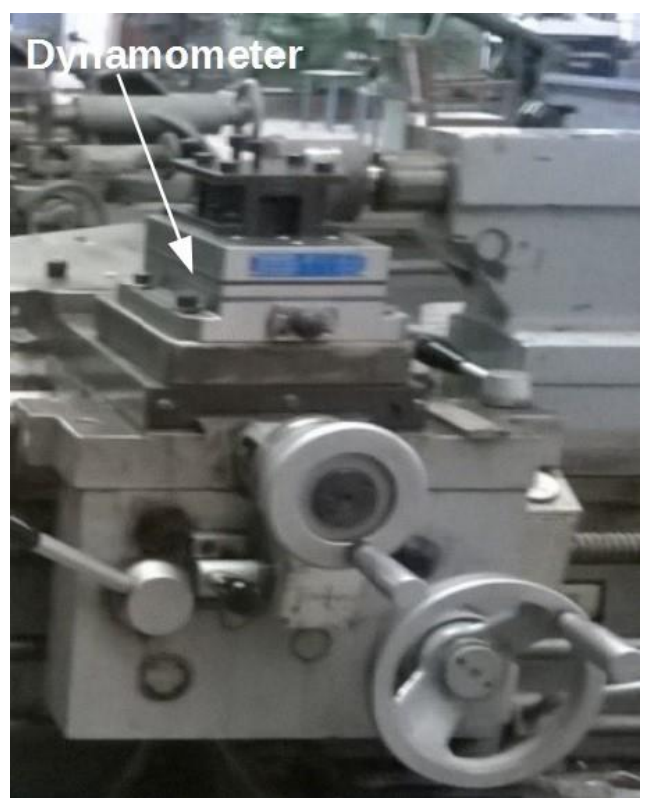

Fig. 1 Experimental setup

\subsection{Experimental design}

The present study focuses on process parameter selection based on multiple criteria of process stability and lower cutting time. The experimental design for process parameter selection must have lower number of experiments to allow for exploring more levels of process parameters. The experiments were planned such that the analysis of the first set of experiments would be used to decide the parameter levels for the next round. The first round of experiments was based on the recommendations provided by the tool manufacturer [19]. Round 2 was conducted to further reduce machining time by increasing the cutting speeds. In Round 3, further higher speeds and moderate feeds were used to check if machining time could be reduced. The details of the experimental design are as follows:

\subsubsection{Round 1}

The input parameters and their levels are shown in

Table 1. To reduce the number of experiments conducted, a 2-level fractional factorial design with a center point that's repeated as shown in Table 2 was considered. The center point allows us to make inferences about how the parameter varies in between the two levels.

Table 1 Process parameter levels for Round 1

\begin{tabular}{|c|c|c|c|c|c|}
\hline Symbol & Parameter & Unit & \multicolumn{3}{|c|}{ Levels } \\
\hline A & Speed & $\mathrm{m} / \mathrm{min}$ & 40 & 60 & 80 \\
\hline B & Feed & $\mathrm{mm} / \mathrm{rev}$ & 0.103 & 0.175 & 0.264 \\
\hline
\end{tabular}

\begin{tabular}{|l|l|l|l|l|l|}
$\mathrm{C}$ & Depth of cut & $\mathrm{mm}$ & 0.1 & 0.2 & 0.3 \\
\hline
\end{tabular}

Table 2 Experimental design for Round 1

\begin{tabular}{|l|l|l|l|}
\hline S.No & A & B & C \\
\hline 1 & 1 & 1 & 1 \\
\hline 2 & -1 & 1 & -1 \\
\hline 3 & 0 & 0 & 0 \\
\hline 4 & 0 & 0 & 0 \\
\hline 5 & 1 & -1 & -1 \\
\hline 6 & -1 & -1 & 1 \\
\hline
\end{tabular}

\subsubsection{Round 2}

Based on the results of Round 1, the depth of cut was fixed to $0.1 \mathrm{~mm}$ as vibrations were higher for larger depths of cut. Also, as it is a finishing process, it reduces material wastage. The process parameters and their levels are shown in Table 3 As there are only two parameters, a 2-level full factorial design with a center point that is repeated as shown in Table 4 is used as the experimental design for this round.

Table 3 Process parameter levels for Round 2

\begin{tabular}{|c|c|c|c|c|c|}
\hline Symbol & Parameter & Unit & \multicolumn{3}{|c|}{ Levels } \\
\hline A & Speed & $\mathrm{m} / \mathrm{min}$ & 100 & 120 & 140 \\
\hline B & Feed & $\mathrm{mm} / \mathrm{rev}$ & 0.051 & 0.077 & 0.103 \\
\hline
\end{tabular}

Table 4 Experimental design for Round 2

\begin{tabular}{|l|l|l|}
\hline S.No & A & B \\
\hline 1 & 0 & 0 \\
\hline 2 & 0 & 0 \\
\hline 3 & -1 & -1 \\
\hline 4 & 1 & -1 \\
\hline 5 & 1 & 1 \\
\hline 6 & -1 & 1 \\
\hline
\end{tabular}

\subsubsection{Round 3}

To check if further higher speeds were possible, the experiments were conducted at cutting speed of 160 $\mathrm{m} / \mathrm{min}$, feed of $0.077 \mathrm{~m} / \mathrm{min}$ and depth of cut of $0.1 \mathrm{~mm}$.

\subsection{Data analysis}

The force signal data from each experiment from the designs presented above is stored in comma separated value (CSV) format. The signal corresponding to entry and exit region are removed and only the steady cutting zone of the force signal was used for further analysis.

To study the stability of the process, time variation of statistical parameters has to be considered. In frame statistics, a signal is divided into parts of constant size and statistical parameters are evaluated for each frame. The variation from frame to frame can be used to analyze trend-the variation of statistical parameter with time. In this study, the size of the frame used was 500 samples. Kurtosis and standard deviation were used to analyze the process stability.

Standard deviation is the measure of dispersion from the center. The standard deviation of a force signal is hence related to the variation of force signals from the average value. It can be used as a measure of vibration. 
A non-increasing value of standard deviation while machining means the process is stable. In the present study, the signal was divided into frames of $0.5 \mathrm{~s}$ length and standard deviation was evaluated for each frame.

Kurtosis is a measure of how well the distribution of data is close to standard normal distribution. A kurtosis value of 3 means it is matched with the standard normal distribution. A sudden change in kurtosis with respect to time is an indicator of extreme values in the data. Thus, it can be used to detect extreme values in the measured data. In turning, the extreme values of the force that can damage the tool can be due to material heterogeneity like blow holes or inclusions in a cast material or presence of hard particles in the material (like SiC particles in the present study). The sudden peaks in force show impact loads acting on the tool. Though, a single impact might not cause a catastrophic tool failure, they can cause premature tool failure by edge chipping.

Frequency analysis involves transforming a time domain signal into the frequency domain. The commonly used methods are Fourier transform, Laplace transform, Wavelet Transform and Empirical mode decomposition. The present study considers Fourier transform as it converts a time domain signal into a sum of sinusoids, with each sinusoid defined by frequency, phase and amplitude. These parameters are presented on a frequency response plot, where amplitude and phase details corresponding to each frequency are shown in a graphical form.

DFT was estimated using the Welch method [20]. FFT (Fast Fourier Transform), an efficient algorithm for evaluating DFT was used [21]. For physical interpretation of a signal, autopower spectrum and Power spectral density estimates are used when the signal measured is in Voltage [@stoica2005spectral]. However, in the present study, the force signal was measured in Newton. In this case, there is no physical interpretation for autopower spectrum and Power spectral density.

Anders Brandt [22] suggested the use of linear spectrum estimate and its algorithm for vibration signals. Linear spectrum also known as RMS spectrum, provides an estimate of RMS value at a particular frequency of the signal. The peaks in the signal are hence an estimate of RMS values for the corresponding frequency.

Practical signals have a finite length and a finite a finite sampling frequency, resulting in finite bandwidth of the stored signal. The finite bandwidth of a signal, limits the frequency resolution [22]. Increasing the frequency resolution reduces amplitude accuracy and vice versa. A greater resolution results in lower error in the signal. In the current study, the signals were measured for cutting a length of $100 \mathrm{~mm}$ of the workpiece, which gives a good frequency resolution. A flattop window [23] was applied to the signal reduce amplitude error in Linear spectrum.

\subsection{Round 1}

Experiments were conducted based on the experimental design and parameters as shown in

Table 1 and Table 2. The signal was processed to evaluate linear spectrum and Frame statistics of standard deviation and kurtosis.

Standard deviation was plotted for the duration of cutting to evaluate the stability of the process. As shown in the Fig. 2, the trend is stable for Experiments 3, 4 and 5. The trend value is lowest for Experiment 2. Experiment 6 has an increasing trend. Higher standard deviation means larger vibrations. The standard deviation values in the radial direction directly affect the surface finish. Having a low and stable standard deviation in the radial direction is hence essential. From the above analysis, a stabilizing trend for standard deviation is seen only in experiments 2 and 5. The depth of cut is 0.1 in these 2 cases.

As shown in the Fig. 3, small peaks can be seen in all experiments. The presence of $\mathrm{SiC}$ particles and machining "as cast" material which can have material heterogeneity can be the most possible cause. A very large peak in experiment 6 can be seen at frame number 11. A similar peak was also seen in the feed force plot.

Statistical analysis gives a good idea about the amount of vibration, presence of sudden peaks in the data. But, it does not provide any information about the source of vibration, i.e. what are the dominant frequencies at which the system is vibrating. Linear spectrum is a frequency domain operation that estimates the frequency and amplitude (RMS) values of the components of a time signal using the Fourier transform. This can be useful in identifying the source of vibration. It is also useful for better analysis of the process by comparing with the spectrum of ideal curves like sinusoids. As shown in the Fig. 4, large, high frequency harmonics can be seen in experiments 1 and 3 . It has to be noted that experiments 3 and 4 are conducted at same process parameters. Except for the peak at 4th harmonic, experiments 3 and 4 have a similar linear spectrum shape. The average standard deviation values are close to each other as shown in Table 5. Linear spectrum plots are a direct measure of vibration. Along with standard deviation, they can be used for analyzing vibration and its source.

From round 1, it can be seen that standard deviation values are affected by the large value of depths of cut. Experiment 5 with low depth of cut, high cutting speed and low feed was found to be better than other process parameters. It has to be noted that the standard deviation values in the radial direction in experiment 5 are still higher. Hence, for round 2, higher speeds, lower feeds and depth of cut at $0.1 \mathrm{~mm}$ have been chosen.

\section{Results and discussion}



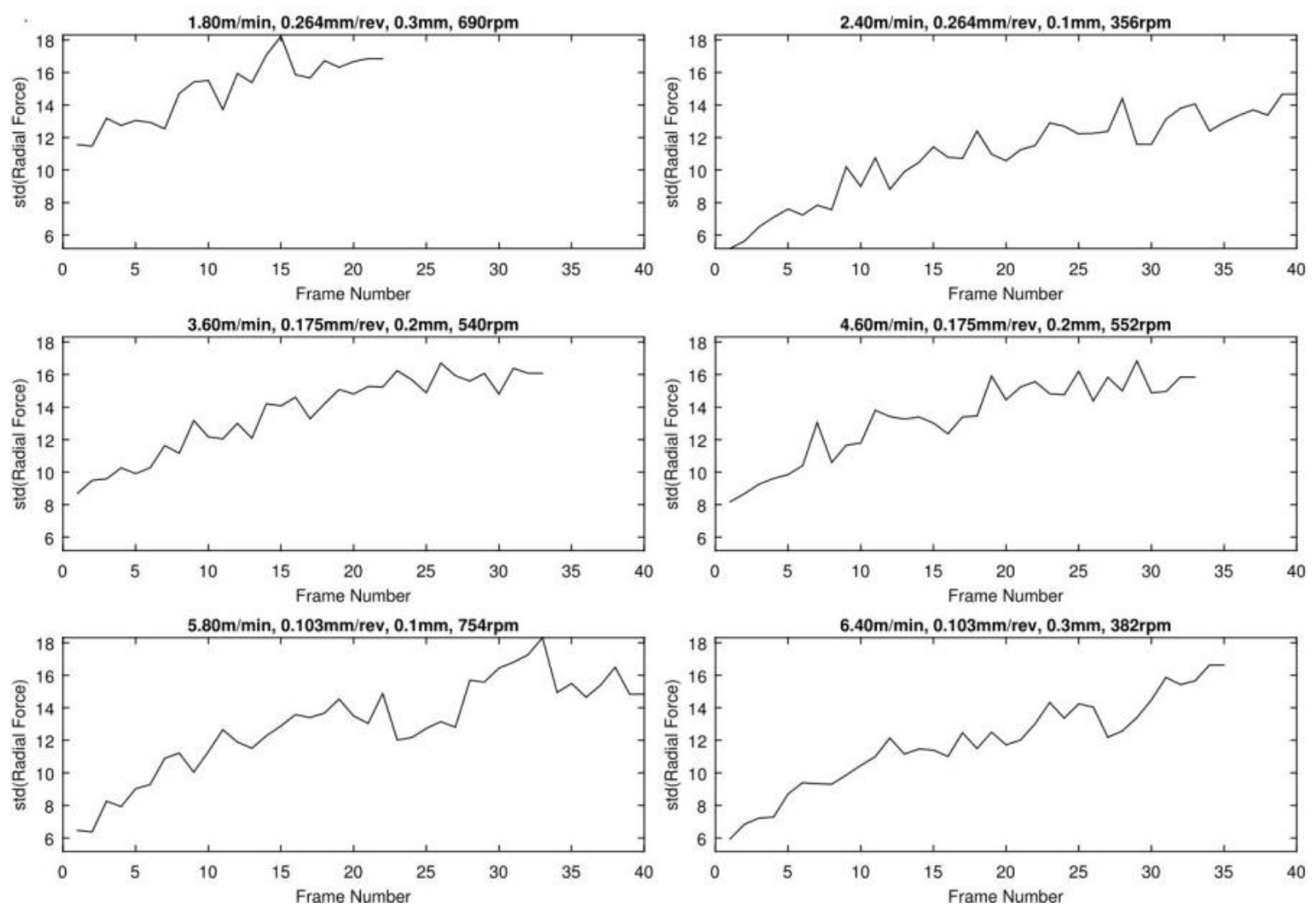

Fig. 2 Standard deviation plots for Round 1
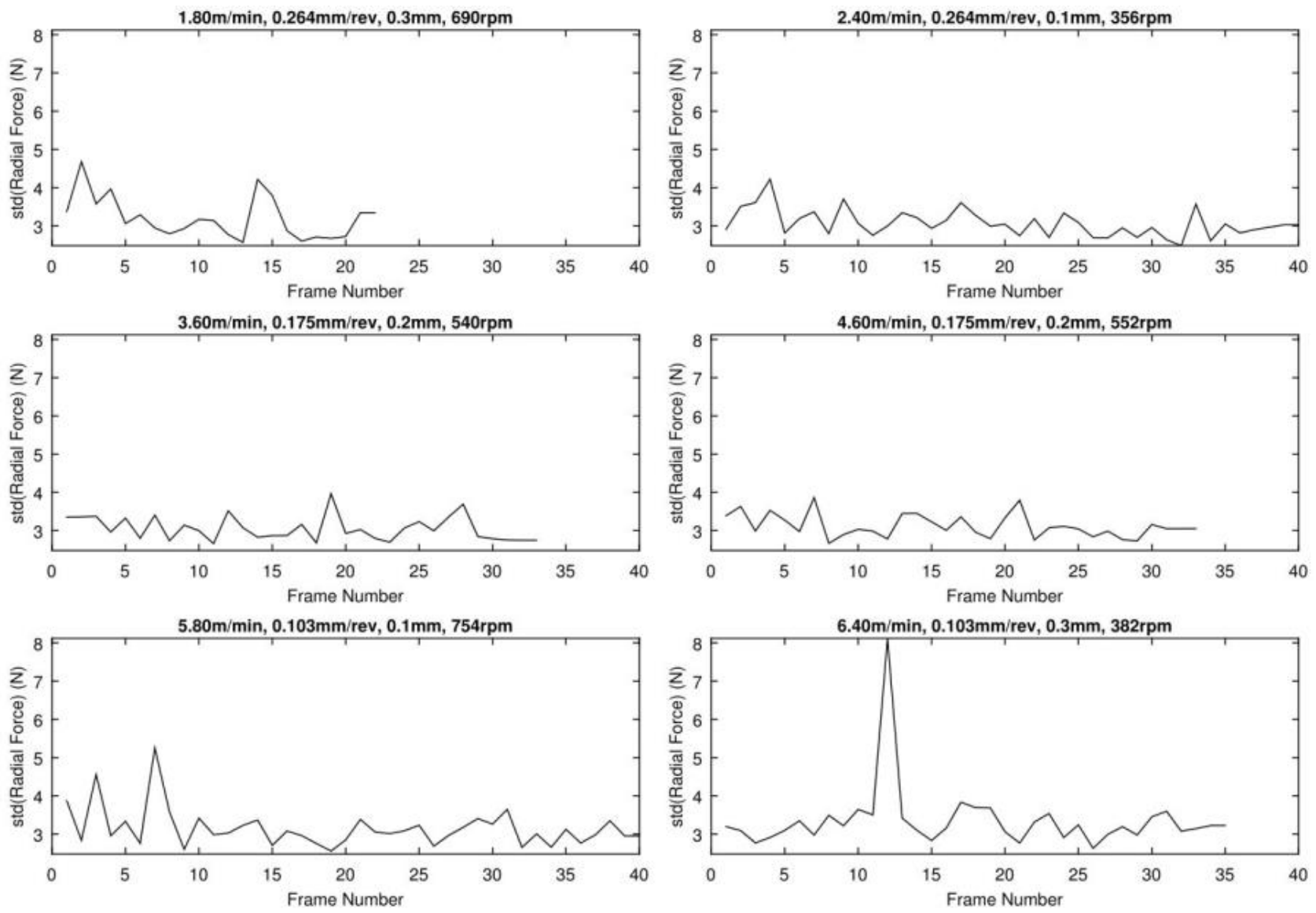

Fig. 3 Kurtosis plots for Round 1 

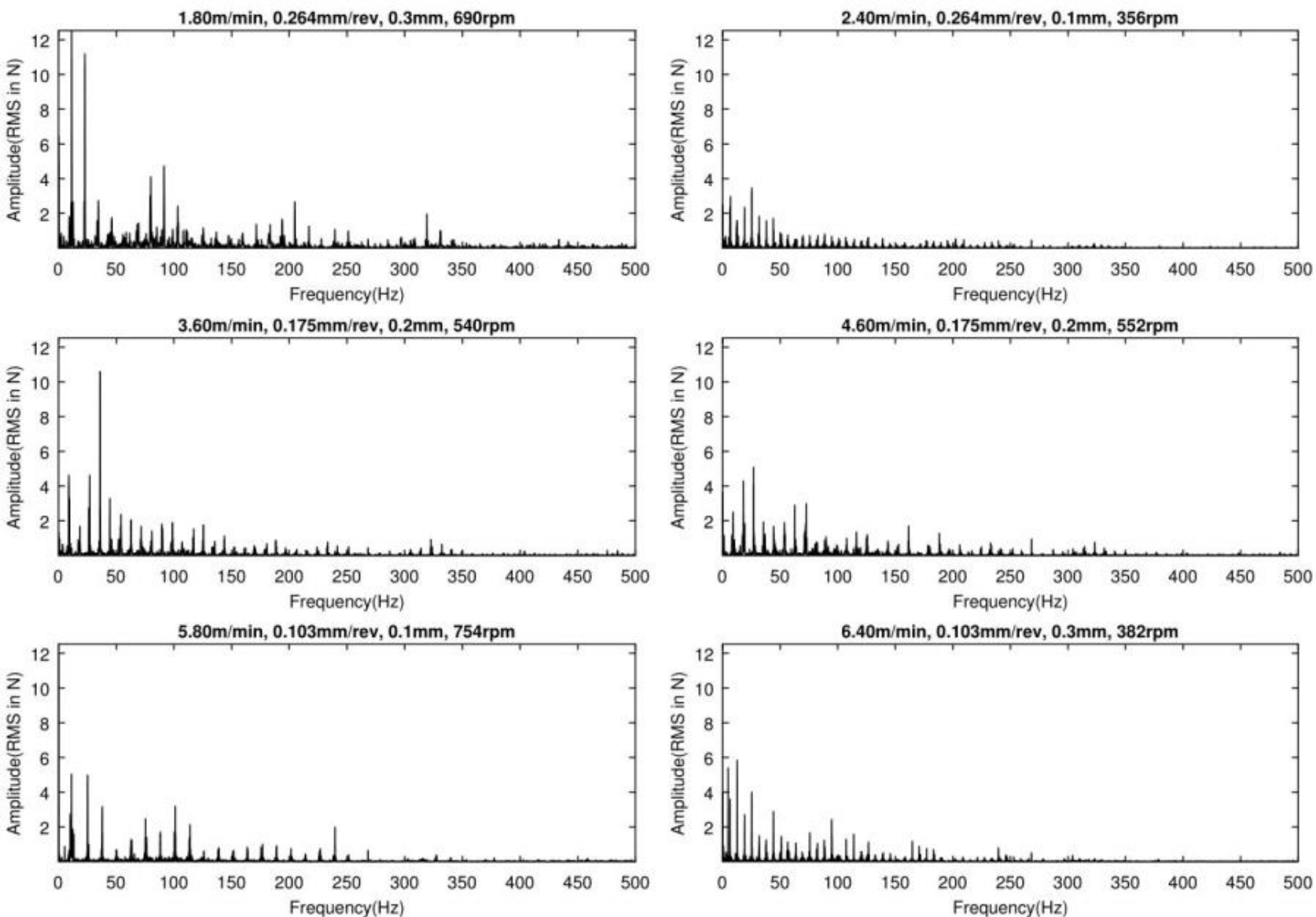

Fig. 4 Linear spectrum plots for Round 1
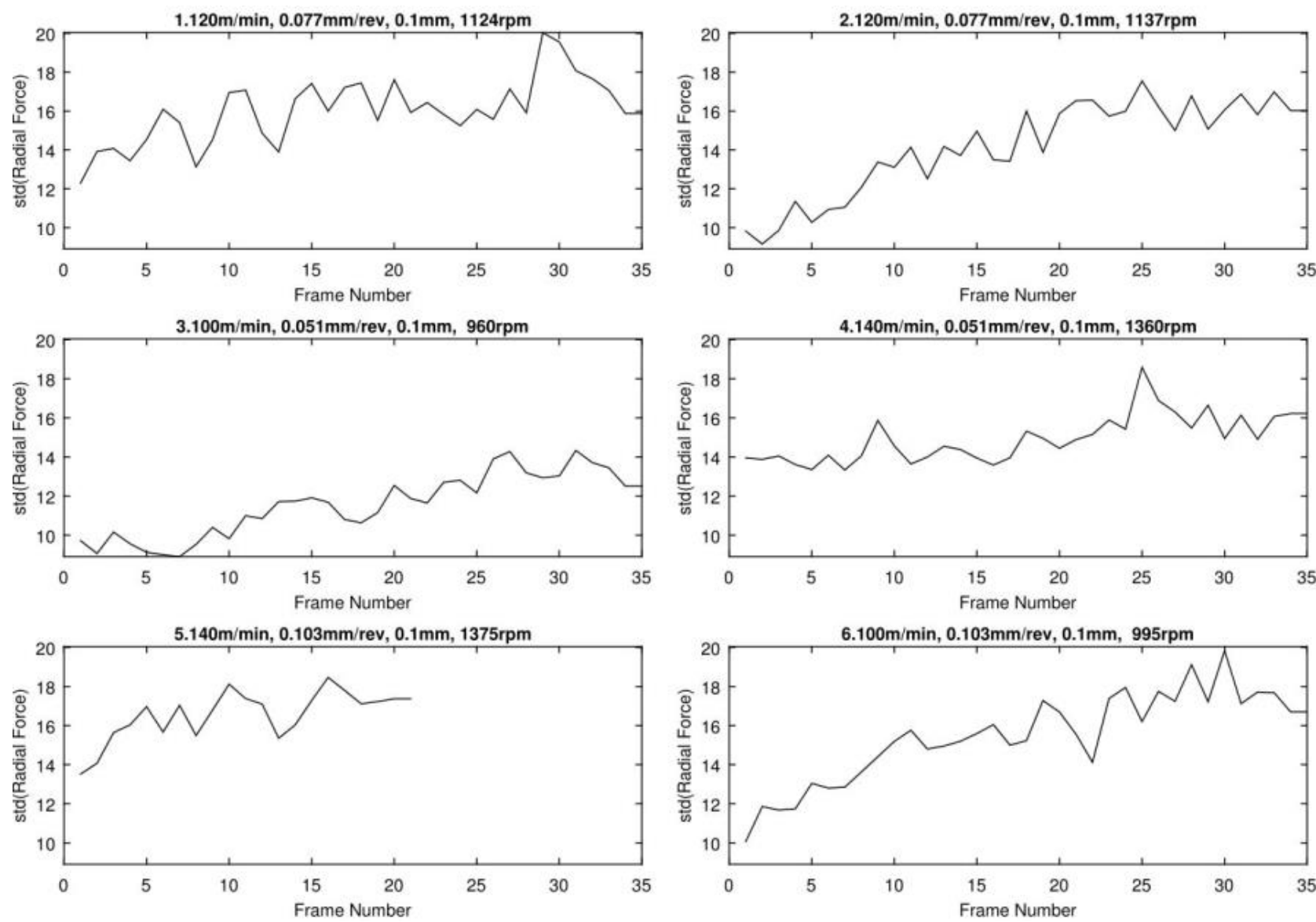

Fig. 5 Standard deviation plots for Round 2 

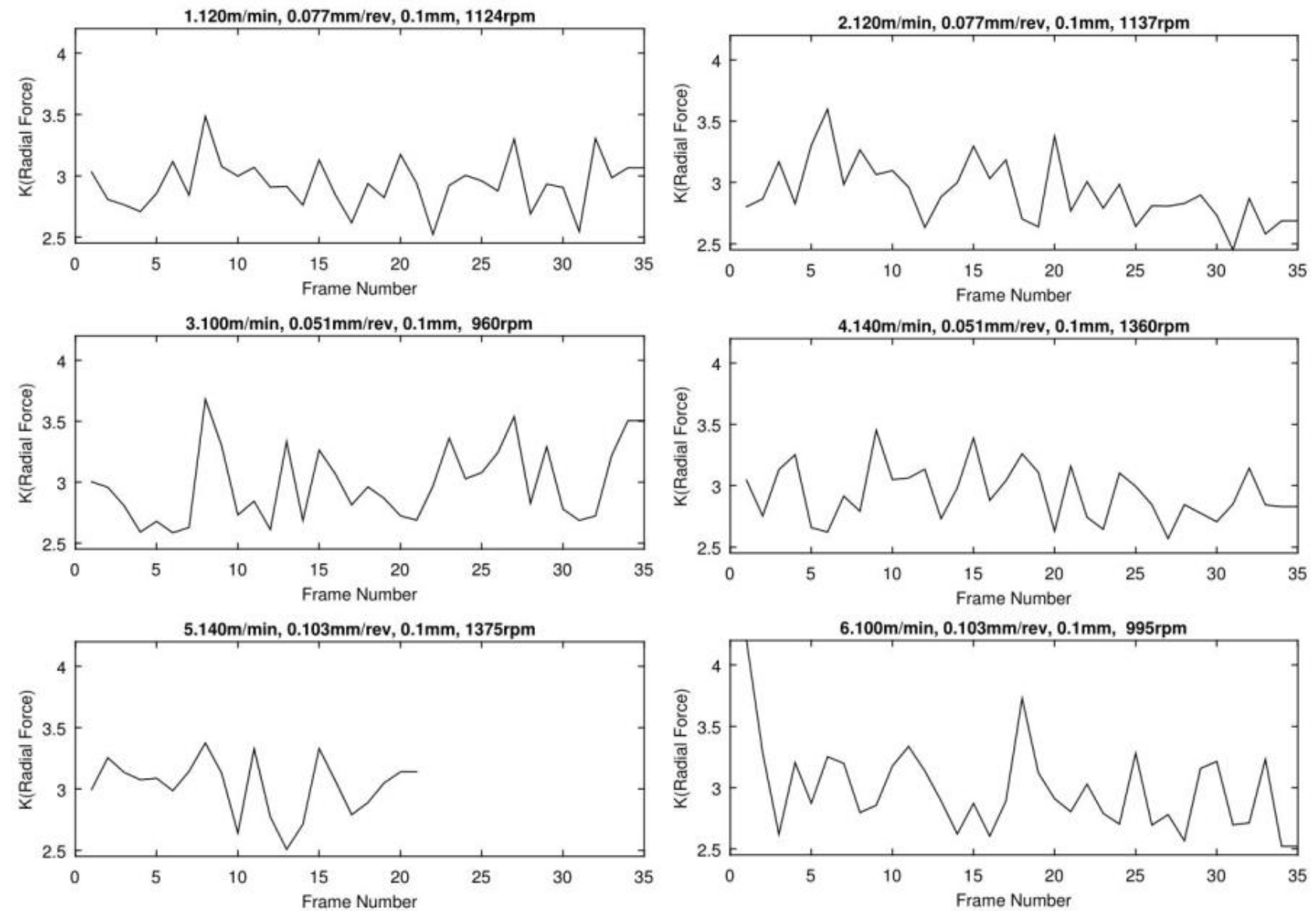

Fig. 6 Kurtosis plots for Round 2
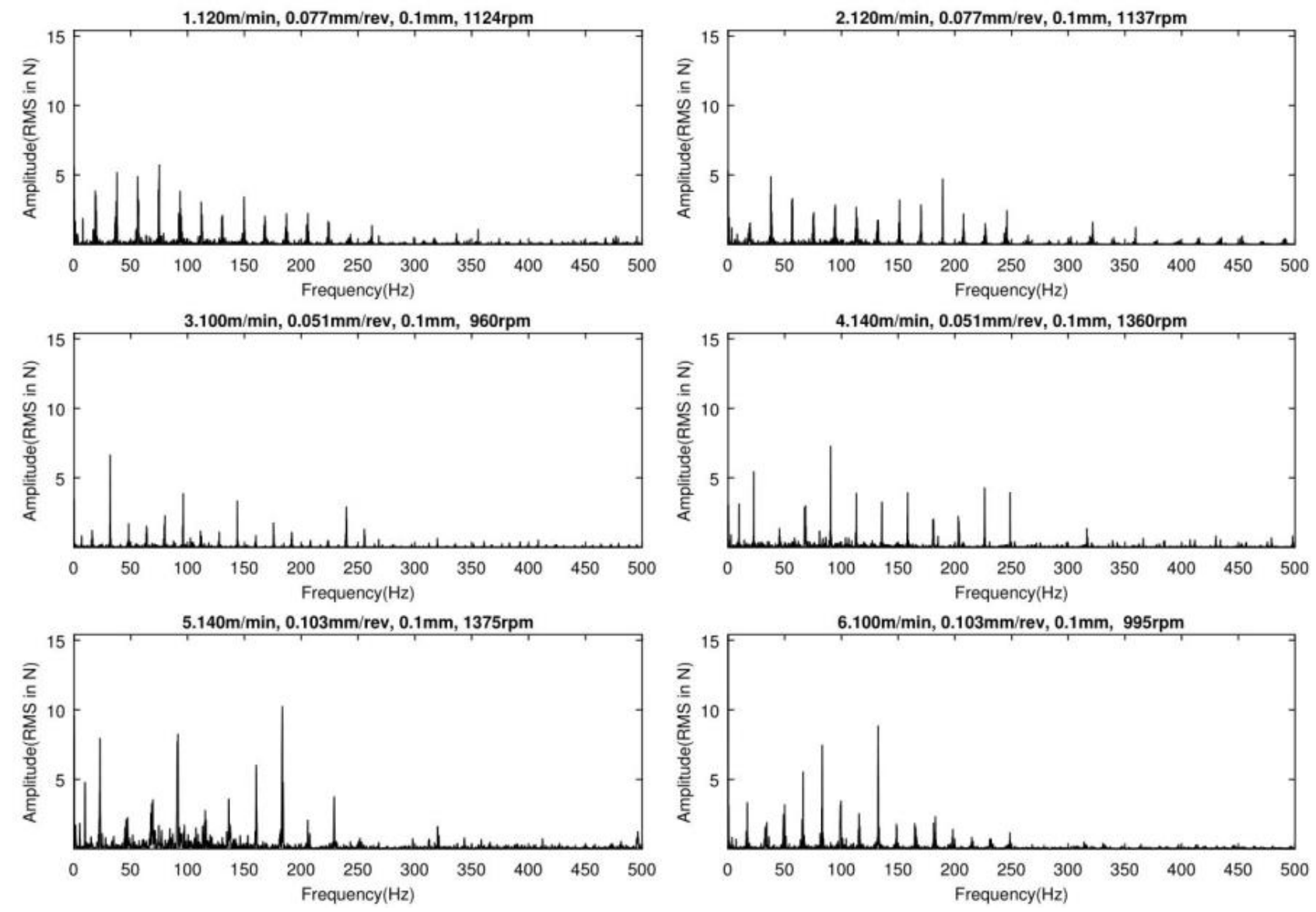

Fig. 7 Linear spectrum plots for Round 2 
Table 5 Summary of the results

\begin{tabular}{|c|c|c|c|c|c|c|c|}
\hline Round & $\begin{array}{l}\text { Exp } \\
\text { No }\end{array}$ & $\begin{array}{l}\text { Cutting speed } \\
(\mathrm{m} / \mathrm{min})\end{array}$ & $\begin{array}{l}\text { Feed } \\
(\mathrm{mm} / \mathrm{rev})\end{array}$ & $\begin{array}{l}\text { Depth of cut } \\
(\mathrm{mm})\end{array}$ & $\begin{array}{l}\text { Machining time } \\
\text { (s) }\end{array}$ & $\begin{array}{l}\operatorname{Std}\left(F_{y}\right) \\
(N)\end{array}$ & $\begin{array}{l}\text { Trend } \operatorname{std}\left(\mathrm{F}_{\mathrm{y}}\right) \\
(\mathrm{N} / \mathrm{s})\end{array}$ \\
\hline \multirow[t]{6}{*}{1} & 1 & 80 & 0.264 & 0.3 & 13.18 & 17.62 & 0.26 \\
\hline & 2 & 40 & 0.264 & 0.1 & 25.54 & 13.80 & 0.2 \\
\hline & 3 & 60 & 0.175 & 0.2 & 25.40 & 16.67 & 0.23 \\
\hline & 4 & 60 & 0.175 & 0.2 & 24.84 & 16.19 & 0.22 \\
\hline & 5 & 80 & 0.103 & 0.1 & 30.90 & 16.31 & 0.21 \\
\hline & 6 & 40 & 0.103 & 0.3 & 61.00 & 15.43 & 0.26 \\
\hline \multirow[t]{6}{*}{2} & 1 & 120 & 0.077 & 0.1 & 27.73 & 18.91 & 0.11 \\
\hline & 2 & 120 & 0.077 & 0.1 & 27.41 & 20.15 & 0.21 \\
\hline & 3 & 100 & 0.051 & 0.1 & 49.02 & 13.55 & 0.14 \\
\hline & 4 & 140 & 0.051 & 0.1 & 34.60 & 16.50 & 0.08 \\
\hline & 5 & 140 & 0.103 & 0.1 & 16.95 & 19.89 & 0.14 \\
\hline & 6 & 100 & 0.103 & 0.1 & 23.42 & 22.30 & 0.19 \\
\hline \multirow[t]{2}{*}{3} & 1 & 160 & 0.077 & 0.1 & 19.61 & 20.86 & 0.16 \\
\hline & 2 & 160 & 0.077 & 0.1 & 19.71 & 19.90 & 0.12 \\
\hline
\end{tabular}

\subsection{Round 2}

Experiments were conducted based on parameters and experimental design given in Table 3 and Table 4. The results are presented in following paragraphs

Standard deviation plots are shown in Fig. 5, All experiments have a stable trend. The value of standard deviation is lower in Experiment 3. As shown in the Fig. 6 , in the kurotisis plots, a comparatively larger peak is present at the beginning of experiment 6 . The peaks in all other cases are small.

Fig. 7 shows the linear spectrum plots of Round 2 . Compared to experiments from Round 1, all the experiments in round 2 have high frequency components. experiments 5 and 6 have large, high frequency components. Experiment 4 has a similar spectrum as experiment 5, except that there is no large amplitude peak in between 150-200 Hz. This has resulted in significantly lower vibration which can be understood from standard deviation of 16.5 in experiment 4 while standard deviation is 19.9 for experiment 5. The amplitudes of peaks are lower in experiment 1 and 2 but their standard deviation values are higher. This is due to the presence of peaks for almost every harmonic.

In Round 2, the standard deviation trend was stable for most of the experiments. Lower standard deviation was in experiment 3 followed by experiment 4 . However, the machining times for these two cases is very high. These parameters are useful when very high surface finish is desired. In other cases we can use high cutting speeds as in experiment 4 and 5 .

\subsection{Round 3}

To check if further higher speeds and moderate feeds are possible, 2 experiments were conducted at same parameters of cutting Speed $160 \mathrm{~m} / \mathrm{min}$, feed 0.077 $\mathrm{m} / \mathrm{min}$ and depth of cut $0.1 \mathrm{~mm}$. The results are presented in the following paragraphs.
As shown in theFig. 8 Fig. [\#fig-R3stdFy], the standard deviation trends are similar except for the last frame numbers as observed in the case of feed force. In Fig. 9, the variation in kurtosis is negligible when compared to round 1 . The kurtosis values as in Round 2 are very close to ideal value 3. As shown in the Fig. 10, The shape of the Linear spectrum is same for both trials except for the peak in between 150 and $200 \mathrm{~Hz}$ in trial 1. This has resulted in a slightly larger value of standard deviation for trial 1 than trial 2 as shown in Table 5
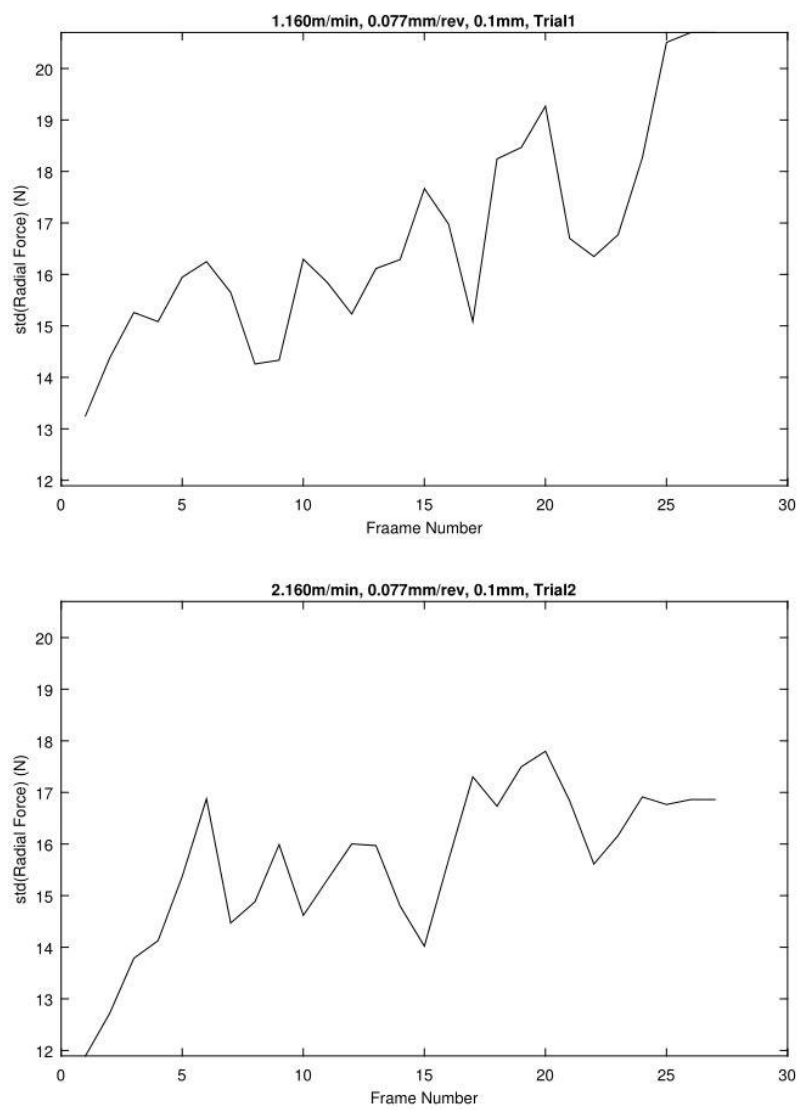

Fig. 8 Standard deviation plots for Round 3 

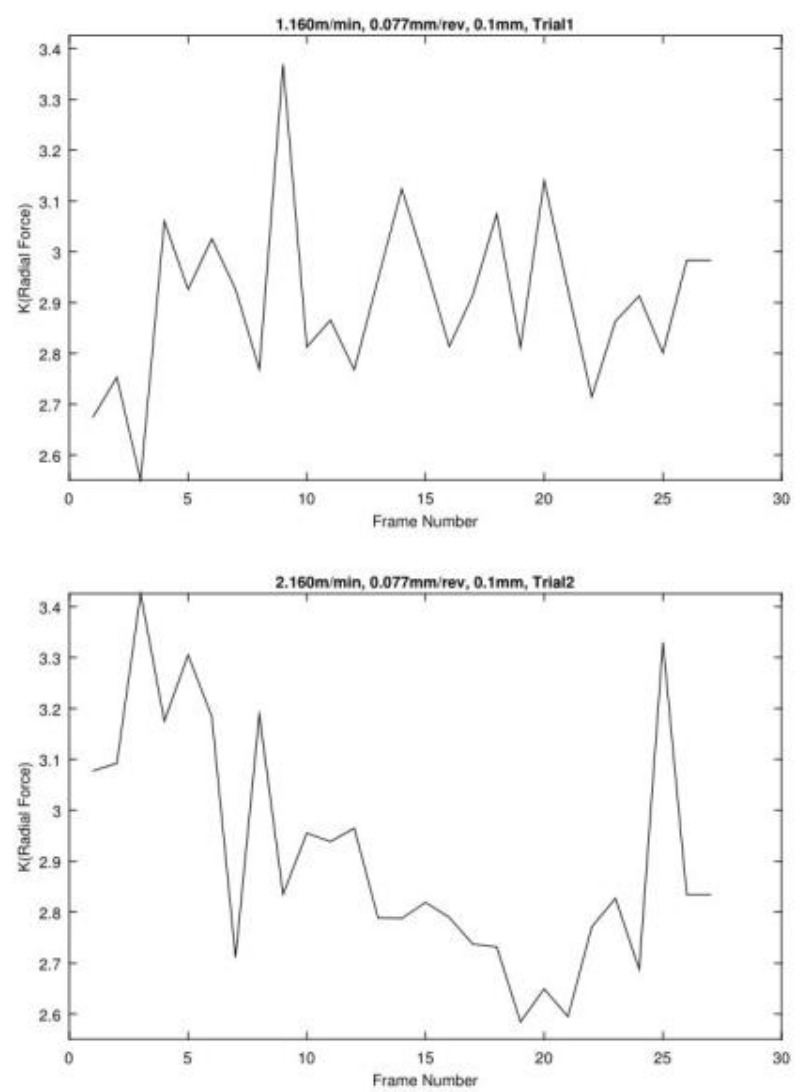

Fig. 9 Kurtosis plots for Round 3
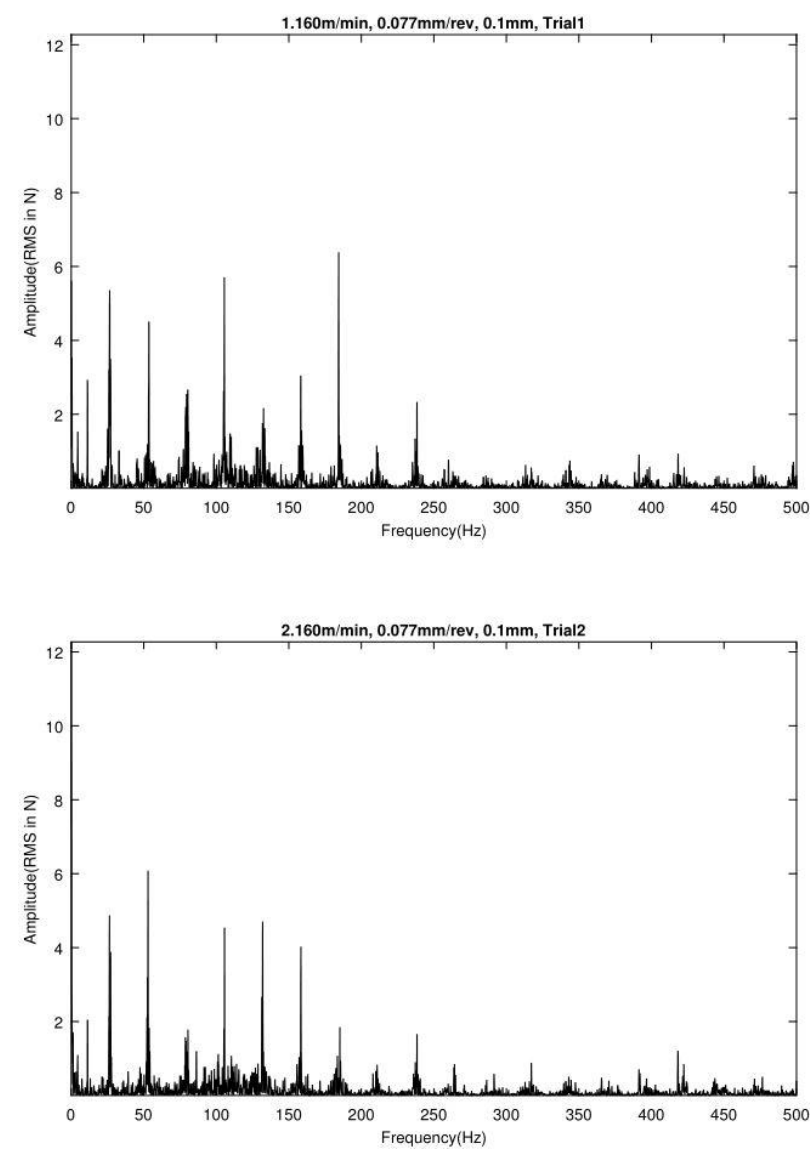

Fig. 10 Linear spectrum plots for Round 3

From the above discussion, it can be summarized that large peaks in kurtosis values were observed in the case of higher depth of cuts and feed. As the depth of cut was reduced in the next rounds, such high peaks were not seen. The least amount of vibration in radial direction was for $100 \mathrm{~m} / \mathrm{min}, 0.051 \mathrm{~mm} / \mathrm{rev}$ feed and $0.1 \mathrm{~mm}$ depth of cut. But, this results in larger machining times. An alternative would be to select $140 \mathrm{~m} / \mathrm{min}$ as cutting speed. With a moderate increase in vibration in radial direction, the cutting time can be reduced by $29.4 \backslash \%$ as shown in Table [\#tab-results]. The best possible machining time with a stable process was at $140 \mathrm{~m} / \mathrm{min}$ cutting speed, $0.103 \mathrm{~mm} / \mathrm{rev}$ feed and $0.1 \mathrm{~mm}$ depth of cut.

In comparison with the present study, Ramanujam et al [5] based their optimized results on minimizing average cutting force and surface roughness but have not considered process stability and machining time, which have direct influence on tool life and productivity. Manna et al [12] have conducted experiments up to tool wear, but have considered varying parameters one at a time, thus resulting in greater number of experiments and lack of information of combined effects of process parameters.

The current study presents a detailed analysis of machining process for single pass experiments. It does not consider tool wear experiments. As the focus was on analysing the sensor signals, correlation of standard deviation, kurtosis of force signals to surface roughness or tool wear was not considered. Such an analysis would be useful for useful tool life estimation and thus assist online tool wear monitoring.

\section{Conclusion}

The paper presents a method to analyze dry finish turning of Aluminium Metal matrix composites. The data analysis was automated using a MATLAB program. The following conclusions can be made from the present study:

- The methodology presented for finish turning of metal matrix composites is a general approach that can be applied for analysing sensor signals from any manufacturing process

- Application of frame statistics for standard deviation and kurtosis was presented for analysing process stability

- Linear spectrum and its physical interpretation for force signal analysis have been presented. By providing RMS values for each frequency component of the signal, the estimate can be used along with average standard deviation values for analysing the relative stability of the process at different process parameter conditions.

In finish turning of the $\mathrm{Al}$ metal matrix composite, the vibrations in radial direction were lowest at cutting speed $100 \mathrm{~m} / \mathrm{min}$, feed $0.051 \mathrm{~mm} / \mathrm{rev}$ and depth of cut $0.1 \mathrm{~mm}$. The next better option of using $140 \mathrm{~m} / \mathrm{min}$ as the cutting speed with same feed and depth of cut would result in a reduction of cutting time by $29.41 \%$. The best possible machining time with stable vibrations and minimal effect of material homogeneity was at cutting speed of $140 \mathrm{~m} / \mathrm{min}, 0.103 \mathrm{~mm} / \mathrm{rev}$ feed and $0.1 \mathrm{~mm}$ 
depth of cut. A reduction of $65.2 \backslash \%$ in cutting time when compared with the best stability condition was achieved.

\section{Acknowledgements}

This research did not receive any specific grant from funding agencies in the public, commercial, or not-for-profit sectors.

\section{References}

1. N. Chawla and K. K. Chawla, Metal Matrix Composites, 2. Springer-Verlag, New York, (2013).

2. J. P. Davim, Machining of Metal Matrix Composites. Springer-Verlag, London (2012).

3. C.-W. Chang and C.-P. Kuo, Int. J. Mach. Tools Manuf., vol. 47, no. 1, pp. 141-147 (2007).

4. C. C. Tsao and H. Hocheng, Int. J. Mach. Tools Manuf., vol. 44, no. 10, pp. 1085-1090 (2004).

5. R. Ramanujam, N. Muthukrishnan, and R. Raju, Int. J. Precis. Eng. Manuf., vol. 12, no. 4, pp. 651656 (2011).

6. M. Seeman, G. Ganesan, R. Karthikeyan, and A. Velayudham, Int. J. Adv. Manuf. Technol., vol. 48, no. 5-8, pp. 613-624 (2010).

7. A. K. Sahoo, S. Pradhan, and A. K. Rout, Arch. Civ. Mech. Eng., vol. 13, no. 1, pp. 27-35 (2013).

8. R. K. Bhushan, S. Kumar, and S. Das, "Effect of machining parameters on surface roughness and tool wear for $7075 \mathrm{Al}$ alloy $\mathrm{SiC}$ composite," Int. J. Adv. Manuf. Technol., vol. 50, no. 5-8, pp. 459469 (2010).

9. M. S. Phadke, Quality engineering using robust design. Prentice Hall, (1989).

10. V. N. Nair et al., Technometrics, vol. 34, no. 2, pp. 127-161 (1992).

11. X. Li and W. K. H. Seah, Wear, vol. 247, no. 2, pp. 161-171 (2001).

12. A. Manna and B. Bhattacharayya, J. Mater. Process. Technol., vol. 140, no. 1, pp. 711-716, (2003).

13. R. Sekhar and T. P. Singh, vol. 4, no. 2, pp. 197207 (2015).

14. T. Ozben, E. Kilickap, and O. Caklir, J. Mater. Process. Technol., vol. 198, no. 1, pp. 220-225, (2008).

15. J. Tlusty and G. C. Andrews, CIRP Ann. Technol., vol. 32, no. 2, pp. 563-572 (1983).

16. H. K. Tönshoff, J. P. Wulfsberg, H. J. J. Kals, W. König, and C. A. Van Luttervelt, CIRP Ann. Technol., vol. 37, no. 2, pp. 611-622 (1988).

17. G. Byrne, D. Dornfeld, I. Inasaki, G. Ketteler, W. König, and R. Teti, CIRP Ann. Technol., vol. 44, no. 2, pp. 541-567 (1995).

18. R. Teti, K. Jemielniak, G. O'Donnell, and D. Dornfeld, "Advanced monitoring of machining operations," CIRP Ann. Technol., vol. 59, no. 2, pp. 717-739, (2010)

19. Widia, "Widia 2010 Turning Catalog." (2010).

20. P. D. Welch, IEEE Trans. audio Electroacoust., vol. 15, no. 2, pp. 70-73 (1967).

21. J. W. Cooley and J. W. Tukey, Math. Comput., vol.
19, no. 90, p. 297, (1965).

22. A. Brandt, Noise and vibration analysis: signal analysis and experimental procedures. John Wiley \& Sons, (2011).

23. S. Gade and H. Herlufsen, "Use of Weighting Functions in DFT/FFT analysis," $B \& K$ Tech. Rev., vol. 3 (1987). 